race the tide was flooding up the Solent at the start, and some used the yachtsman's ploy of hugging the Hampshire shore to avoid the worst of the tide, but it may be that a planing boat with very little of its hull in the water is little affected by the surface tidal current. The tide was flooding up Channel until about 1 3.30, so it was very much in competitors' interest to get round Portland Bill before then. Few made it.

Across Lyme Bay one has to decide not on the shortest course, but the quickest. In 1961 it paid handsomely to go i 8 miles further by taking a detour in towards the Dorset coast and thus get in sheltered water sooner. In 1962 it was somewhat calmer and paid not to deviate too far off rhumb line. But, unless it is flat calm, there will always be a case for striking the optimum course to give the quickest crossing.

The important thing is to get there in one piece.

\title{
Collision Avoidance by Discussion
}

$$
\text { from Captain F. J. Wylie, R.N. (Ret.) }
$$

'Collision Avoidance by Discussion' (see this Journal, p. 159) has been part of the radar controversy since it began. If it is assumed, as I think it must be, that no solution is acceptable which does not apply to multilateral situations, the complications inherent in such a proposal become apparent. A bilateral agreement, for example, on alterations of course will be based on the situation as seen at a given moment; this may change drastically within minutes as other ships' bilateral or monolateral decisions are put into effect. These may necessitate changes in intention and further confabulation, possibly now with others than the ship originally contacted, and so on.

The ability to communicate pre-supposes :

(a) that everyone has v.h.f. $\mathrm{R} / \mathrm{r}$ using a common calling channel,

(b) that everyone can be positively identified on everyone else's radar, and

(c) that instant communication is possible in the event of intentions being changed or other matters of urgency arising.

The original premise concerning multilateral situations is fundamental because the master cannot be expected to adopt different processes depending on the number of ships around him. The requirement for 100 per cent participation has the same basis; if only a proportion of ships can be identified or are able to communicate the situation becomes impossible. The same basis applies to the insistence on immediate communication.

It is clearly impossible to guarantee either $(a),(b)$ or $(c)$. Even if it could be assumed that every ship giving an echo on the radar screen had the correct equipment, switched on and in working order, the simple fact of the availability of the communications circuit without delay to any ship out of perhaps 20 or 30 within range of one another could certainly not be taken for granted. 
When to all this is added the distinct possibility of language difficulties and methods of expression or of misinterpretation of the radar picture, it is difficult to avoid the conclusion that silence would be golden and speed reduction a better risk than talk.

\section{Radar Displays}

$$
\text { from J. A. Glasgow }
$$

IN a recent contribution to Forum by Commandant L. Oudet (Journal, 17, 88) the problem of the rational form that marine radar displays should take has been raised. The old argument of 'ship's head upwards' or 'north upwards' may be resolved by a combination of the best of both systems without compromise to either school of thought.

Before starting on how this may be achieved a short digression on terminology should not be out of place. The advantages in the use of a 'north upwards' display, i.e. true bearings, lack of smear, accurate plotting and the ability to add 'true motion' do not stem fundamentally from the fact that north is at the top but because the picture is 'compass stabilized'. The 'north up' condition is purely a matter of convenience. The 'north upwards' display would be better termed 'compass stabilized north upwards'.

The type of display that Commandant Oudet calls for is one in which the navigator would see the screen just as he sees the compass card or the sea-scape around him'. The point to be taken from this is that the compass card is naturally compass stabilized and also that on changing course the ship rotates round the compass card, i.e. the compass rotates relative to the ship. To obtain the best radar presentation these two requirements must be met-first of all, the display must be compass stabilized and, secondly, it must be capable of the proper rotation as and when the ship changes her heading. The result is a "compass stabilized ship's head upwards' display. This will give the ease of interpretation of a 'ship's head upwards' display together with true bearings, no smear, true motion if required and also accurate plotting which maintains its validity during yawing and changes in course.

Such a display (the 'Argus') has been developed by the Marconi Company and is already in use at sea. In this particular equipment the operation may be described quite simply. First, the tube, bearing scale and plotter (if fitted) are fixed together but are capable of rotating within the display unit under the control of the compass transmitter. Secondly the c.r.t. trace itself is compass stabilized. Assume as a start that the $0^{\circ}$ or North on the bearing scale is at the top of the display and the tube is held stationary. A conventional 'compass stabilized north upwards' display is now seen and the heading line will show the true direction of the ship's head. The whole assembly of c.r.t., bearing scale and plotter is now rotated until the heading line is upwards. On changing course the transmitting compass now stabilizes not only the trace on the tube but also the tube in the display unit. It is the combination of these actions together that gives the required display, i.e. 'Compass stabilized ship's head up'. 